Article

\title{
Physical and Monetary Methods for Estimating the Hidden Trade of Materials
}

\author{
Wei-Qiang Chen ${ }^{1,2,3, * \mathbb{D}}$, Zi-Jie Ma ${ }^{1,2,3}$, Stefan Pauliuk ${ }^{4}$ and Tao Wang ${ }^{5,6}$ \\ 1 Key Lab of Urban Environment and Health, Institute of Urban Environment, Chinese Academy of Sciences, \\ Xiamen 361021, China; zjma@iue.ac.cn \\ 2 Xiamen Key Lab of Urban Metabolism, Xiamen 361021, China \\ 3 University of Chinese Academy of Sciences, Beijing 100049, China \\ 4 Industrial Ecology Group, Faculty of Environment and Natural Resources, University of Freiburg, \\ Tennenbacher Strasse 4, D-79106 Freiburg, Germany; stefan.pauliuk@indecol.uni-freiburg.de \\ 5 Institute for Advanced Study, Tongji University, Shanghai 200092, China; a.t.wang@foxmail.com \\ 6 UNEP-Tongji Institute of Environment for Sustainable Development, Tongji University, \\ Shanghai 200092, China \\ * Correspondence: wqchen@iue.ac.cn; Tel.: +86-0592-6190763
}

Received: 8 March 2019; Accepted: 3 May 2019; Published: 6 May 2019

\begin{abstract}
The hidden trade of a material (e.g., aluminum) refers to the trade of that material embedded in final products (e.g., automobiles). There are two methods for estimating the hidden trade amount of materials: (1) the physical method relies on the physical trade data (measured by physical units) in which products are categorized according to the standard international trade classification codes or the harmonized system codes; and (2) the monetary method relies on the monetary trade data (measured by monetary units) in which products are categorized in accordance to the sectors of an input-output (IO) table. Information on material concentrations in products can be relatively quickly estimated by an IO-based model in the monetary method, but will have to be collected from various sources with intensive time cost in the physical method. Exemplified by the U.S. hidden trade of aluminum, iron, and copper in 2007, this study attempts to compare the two methods. We find that, despite the unavoidable but reasonable differences in the amounts of three metals trade, the results generated by the two methods are consistent with each other pretty well for final products at the level of end-use product groups (e.g., total transportation facilities). However, the comparison for specific products (e.g., automobiles) is challenging or does not generate consistent enough results. We suggest that similar estimations be done for more materials, more countries/territories, and different years, to gain experience, reduce estimation time and costs, and increase the knowledge base on metal flows in society.
\end{abstract}

Keywords: material flow analysis; hidden trade of materials; anthropogenic metal cycles; industrial ecology

\section{Introduction}

Industrial material consumption has increased more than 20-fold over the last 100 years [1] and is now seen as a major hindrance to sustainable development [2]. The link between consumption and material extraction activities is often indirect, via the import of material-intensive commodities [3]. Therefore, trade flow analysis is an important part of studies on the linkage between resource extraction and consumption, in particular, in studies applying material flow analysis (MFA). Research topics that require the study of material flows in trade include: the calculation of material footprints, the estimation of final material consumption and stock formation, the assessments of criticality and vulnerability 
to supply restrictions, the determination of resources efficiency or materials productivity, or the quantification of embedded material flows for purposes of carbon, water, and other taxation [4-10].

Materials can be traded in various forms, including ore, concentrates, raw and refined metals, or alloys. Moreover, the material trade embedded in final products is defined as "hidden" trade by [11], because the quality and quantities of materials contained in traded final products are not obvious. This situation is different from the trade of materials in the forms of ores, concentrates, scrap, refined metals, or even semis for which it is usually easy to identify a list of products containing the concerned material. The notion of hidden trade used here refers to materials physically embedded in manufactured goods. This notion is different from indirect material consumption used for the concepts of raw material equivalents and total material consumption, which are part of economy-wide material flow accounting and assessments of associated (or embodied) material flows in material footprint calculations [12]. The determination of hidden material trade embedded in traded final products has been a challenge for MFA researchers. Johnson and Graedel [11] applied a method (which we termed the physical method) to estimate the U.S. trade of copper, silver, chromium, lead, and zinc embedded in semis and final products, and concluded that the hidden trade of materials in final commodities accounts for a significant share in the total trade for each of these five metals in the United States. This physical method was also used in many other studies that are based on the stocks and flows framework developed by the Yale Center for Industrial Ecology [13-16] and beyond [17-19]. It is also referred to as a "bottom-up" method because high-resolution product-level trade flow data are multiplied with their respective material compositions.

The physical method for estimating the trade of materials embedded in final products consists of the following steps (Figure 1): (1) identify a list of final products (e.g., air conditioners or automobiles) that contain the concerned materials; (2) obtain the physical trade data (measured by physical units, such as kilogram, ton, or item) for final products from national customs statistics, which are also collected by the United Nations and are available on the UN Comtrade Database [20]; (3) collect data on material concentrations per physical unit of final products, such as weight percentage of copper in air conditioners or kilogram of aluminum per automobile; and finally (4) multiply the physical trade data of final products with their material concentrations to calculate the hidden trade of materials embedded in final products. By taking advantage of customs statistics, the physical method can be used to quantify the hidden trade of materials for many specific products, provided that information on their material concentrations is available. However, the physical method has some challenges: (1) it is difficult to identify a complete list of final products; (2) the physical trade data are not available for all products in all years on the UN Comtrade Database, and therefore, in many cases, it is necessary to apply the monetary trade data to infer the physical trade $[14,16]$, which will result in further uncertainties; and (3) it is difficult to find data on material concentrations for a majority of final products. Consequently, it is usually very time-consuming to apply the physical method in the MFA studies.

By combining the waste input-output material flow analysis (WIO-MFA) model with Japanese trade statistics, Reference [21] proposed another method (which we termed the monetary method) for quantifying the flows of materials embedded in traded commodities and applied it to estimate Japan's trade of iron and aluminum embedded in all products (Figure 1). Steps constituting the monetary method are similar to those of the physical method. However, the monetary method is different from the physical method mainly in three aspects: (1) the traded final products are grouped in accordance to the input-output $(\mathrm{IO})$ sectors in the monetary method, while they are classified by either the standard international trade classification (SITC) codes or the harmonized system (HS) codes in the physical method. The comparative of the two classification systems is provided in Supplementary Materials (Table S1); (2) data on the trade of final products used in the monetary method are measured by monetary units (such as U.S. dollars) rather than by physical units; and (3) material concentrations of traded final products used in the monetary method are inferred by the WIO-MFA model and are measured by weight per monetary unit, such as kilogram of aluminum per constant U.S. dollar. One can also speak of the "top-down" method, because aggregate inter-industry flow statistics from 
the System of National Accounts are used instead of product-level data. Compared to the physical method, the monetary method has at least two advantages: (1) it enables researchers to infer material concentrations for all concerned final products just by using the IO-based WIO-MFA model, therefore avoiding spending a lot of time collecting data on metal concentrations; (2) unlike trade data in physical units that sometimes are not recorded in the customs statistics, trade data in monetary units always exist; especially for the United States and Japan, these monetary trade data are already well compiled in their IO table with $\approx 400$ sectors [22,23], thus can be directly used and will help save a great deal of time.

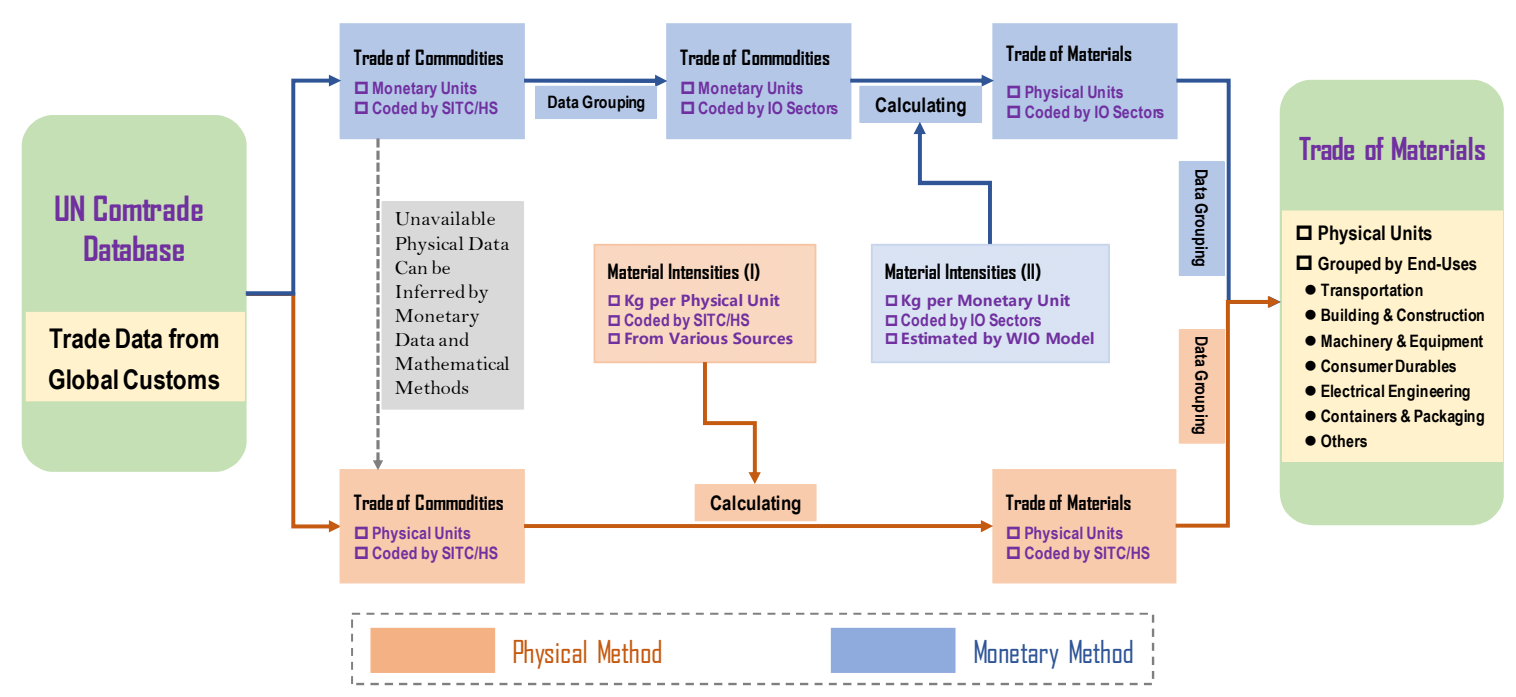

Figure 1. Schematic diagram of physical and monetary methods for estimating the hidden trade of materials.

Besides the abovementioned publications, there have been quite a few other cases of material trade flow analysis applying either the physical method [24-29] or the monetary method [30-32], and some of these studies even analyze the global supply chain or network of materials among countries and territories. The salient findings of these studies are reasonable, such as that at the final goods level, Japan is a net exporter of iron and aluminum embedded in final products because it has been a provider of automobiles and many other manufactured products to the world [21]. However, all studies we have come across use either the physical method or the monetary method, and few have made a detailed comparison of their results with those estimated by the respective other method. The differences of hidden material trade estimates resulting from these two methods, as well as their uncertainties and robustness, have not been explored sufficiently. In particular, it is currently unclear whether the monetary method leads to results of acceptable accuracy, so that it could be applied more broadly as a time-saving alternative to physical bottom-up estimates of material embedded in traded commodities. Here, a first step towards such a comparative assessment is taken. By using the results of several former MFA studies applying the physical method [14,33] and studies on material flow networks applying the monetary method [34,35], the 2007 U.S. hidden trade of three metals including aluminum, copper, and iron were estimated using both the physical and the monetary methods. The concerned products include both semis and final products at the end-use product group level. We present the methodology, data, and results for seven groups of manufactured products and discuss the differences between and uncertainties of the two estimates.

\section{Materials and Methods}

The steps and data sources of estimating hidden materials trade are demonstrated in Figure 1. Originally, all trade data come from the customs statistics of countries or territories. The aluminum, copper, and iron trade analyzed in this study refers to the trade of three metals measured in physical 
weight unit (metric ton) between the United States and the rest of the world in 2007. The concerned products containing metals include semis and final products but exclude ores (such as bauxite), metallic oxide or hydroxide, unwrought metals, scrap, and end-of-life products. The table of different stages of the products lists (take aluminum as an example) is provided in Table S2 (Supplementary Materials). A list of products for each estimating method is provided in Tables S3-S5 (Supplementary Materials) for each metal.

The import, export, and net import of aluminum, copper, and iron embedded in semis and final products using the physical method are estimated by equations below, respectively:

$$
\begin{gathered}
P_{-} \text {Flow }_{i}^{\text {Im, } j}=P_{-} \text {Flow }_{i}^{\text {Im,Pro }} \times C_{i}^{j, I m} \\
P_{-} \text {Flow }_{i}^{E x, j}=P_{-} \text {Flow }_{i}^{E x, P r o} \times C_{i}^{j, E x} \\
P_{-} \text {Flow }_{i}^{\text {NIm, } j}=P_{-} \text {Flow }_{i}^{\text {Im, } j}-P_{-} \text {Flow }_{i}^{E x, j}
\end{gathered}
$$

where $P_{-} F l o w w_{i}^{I m, P r o}$ and $P_{-} F l o w w_{i}^{E x, P r o}$ represent, in the physical method, the import and export of product $i$ that are listed in the Tables S3-S5 (Supplementary Materials), respectively, while $C_{i}^{j, I m}$ and $C_{i}^{j, E x}$ are the average metals ( $j$ represent aluminum, copper, and iron) concentrations in imported and exported product $i$, respectively. Theoretically, $C_{i}^{j, I m}$ and $C_{i}^{j, E x}$ should be different. However, it is almost impossible to accurately estimate $C_{i}^{j, I m}$ because products can be imported from any country or territory outside the United States. Therefore, we assume that $C_{i}^{j, I m}$ equals $C_{i}^{j, E x}$ for each product, meaning that a product imported into the U.S. is regarded to have the same average metals concentration as that produced in the U.S. (however, note that $C_{i}^{A l, I m}$ values for automobiles and light trucks in the MFA study [14] are assumed to be the same as those in Japan, which is different from what we do in this study).

As for the monetary method, the hidden trade values of metals are estimated by equations below, respectively:

$$
\begin{aligned}
& \text { M_Flow } w_{n}^{I m, m}=M \_F l o w w_{n}^{I m, P r o} \times C_{n}^{m, I m} \\
& \text { M_Flow } w_{n}^{E x, m}=\text { M_Flow }{ }_{n}^{E x, \text { Pro }} \times C_{n}^{m, E x} \\
& \text { M_Flow }{ }_{n}^{\text {NIm }, m}=\text { M_Flow }{ }_{n}^{\text {Im, } m}-\text { M_Flow } w_{n}^{\text {Ex }, m}
\end{aligned}
$$

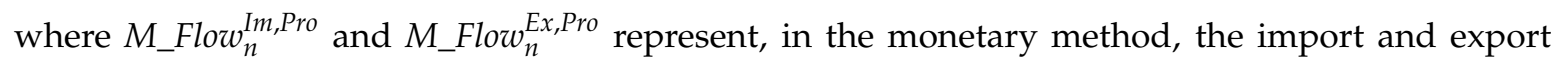
of product $n$ that are also listed in the Tables S3-S5 (Supplementary Materials), respectively. The products here are grouped in accordance to the IO sectors. While $C_{n}^{m, I m}$ and $C_{n}^{m, E x}$ are the average metals ( $m$ represents aluminum, copper, and iron) concentration in imported and exported product $n$, respectively.

Data on trade of semis and final products used in the physical method are collected from the UN Comtrade Database [20] classified by the SITC-1 codes (Table S6, Supplementary Materials). Information on the metals concentration used for the physical method is collected from reports, academic papers, and other publications (details are listed in [14] as well as its Supplementary Materials). Data on the trade of products used in the monetary method are those compiled in the 2007 U.S. IO table (with 389 sectors) as part of final demands [22]. The metals concentration per monetary unit of economic output for each product group is estimated by a method described in a relevant study [34]. Note that in the 2007 IO table, all semis are reported to be produced mainly in one product group (Aluminum Product Manufacturing from Purchased Aluminum), and therefore, only the total of all semis trade (rather than classified into plate, sheet, extrusions, foils, etc.) is estimated in the monetary method.

All final products were grouped into seven end-use product groups according to a method provided by [36]: Transportation (Trans), Building \& Construction (B\&C), Machinery \& Equipment 
(M\&E), Consumer Durables, Electrical Engineering (EE), Containers \& Packaging (C\&P), and Other. Unfortunately, no product was classified into the C\&P product group in the physical method due to the difficulty of identifying suitable products based on the SITC-1 codes [14]. Bicycles, which are classified as Consumer Durables by [36], are grouped into the Trans product group in this study because they are listed together with motorcycles in both product lists (Tables S3-S5, Supplementary Materials) and we think it more reasonable to regard them as transportation facilities. The Trans product group is divided into some sub-product groups as appropriate (Tables S3-S5, Supplementary Materials). Note that the list and classification of final products for the physical method used in this study is slightly different from those used in our former MFA study [14] (Table S6, Figure S1, Supplementary Materials), because we think that the current list and classification are more reasonable after comparing various lists provided by different publications [16,37-39]. It is necessary to point out that there is no completely objective and correct standard of classifying final products into the product groups or sub-product groups; therefore, the list and classification we use in this study is just what we regard as most reasonable.

\section{Results}

Both import and export estimated by the physical method are between $5 \%$ and $70 \%$ higher than those estimated by the monetary method for total final products, and for four end-use product groups including Trans, B\&C, Consumer Durables, and EE for aluminum and copper (Figure 2a,b). However, for iron, the results estimated by the monetary method are between $35 \%$ and $80 \%$ higher than those estimated by the physical method for three end-use product groups including Trans, $\mathrm{B} \& \mathrm{C}$, and $\mathrm{EE}$ (Figure 2c). As for aluminum, the import and export of semis estimated by the physical method were 1324 and 1045 thousand metric tons (TMTs), respectively. The import of total final products estimated by the physical method for aluminum, copper, and iron were 3767, 2234, and 39,227 TMTs, respectively, and the export amounts were 2030,1277, and 20,658 TMTs, respectively. The biggest difference at the product group level for aluminum and iron comes from the Trans product group. The import and export for aluminum estimated by the physical method were $75 \%$ and $82 \%$ higher than those estimated by the monetary method, respectively. Additionally, for copper, the biggest difference comes from M\&E. Both import and export estimated by the physical method were (almost) 100\% lower than those estimated by the monetary method for the C\&P and Other product groups for three metals, because no product was identified for the C\&P product group and only five products were classified into the Other product group in the physical method (Tables S3-S5, Supplementary Materials). The trade of aluminum in the M\&E product group estimated by the physical method was also less than those estimated by the monetary method (Figure 2a), although relatively equal numbers of products were identified in the two product lists (Table S3, Supplementary Materials).

U.S. was a net importer of aluminum, copper, and iron embedded in total final products, as well as in Trans, B\&C, M\&E, Consumer Durables, and EE product groups in 2007 according to both methods (Figure $2 b, d, f)$. This indicates that, despite the differences in the amounts of estimated import and export, the two methods are in accordance with each other in determining whether U.S. was a net importer or a net exporter of final products.

For aluminum (Figure 2b), the differences in net import for Consumer Durables and EE product groups were both very small (less than $2 \%$ ) between the two methods. Again, the biggest difference exists in the Trans product group, with the net import estimated by the monetary method 352 TMTs $(40 \%)$ less than that estimated by the physical method. M\&E is the only product group in which the net import estimated by the physical method is obviously less than that estimated by the monetary method (by 59\%). For copper (Figure 2d), the biggest difference exists in the EE product group, which is the only product group that the net import estimated by the physical method (335 TMTs) is less than that estimated by the monetary method (440 TMTs) (by 24\%). The situation for iron (Figure 2f) is different, except for M\&E product group, all other product groups estimated by the physical method is less than that estimated by the monetary method, and the biggest difference happens in Trans product group 
(by 36\%). The iron estimated by the physical method is more than that estimated by the monetary method (by 40\%) in the M\&E product group. The net import for C\&P and Other product groups were (almost) zero in the physical method for both three metals.

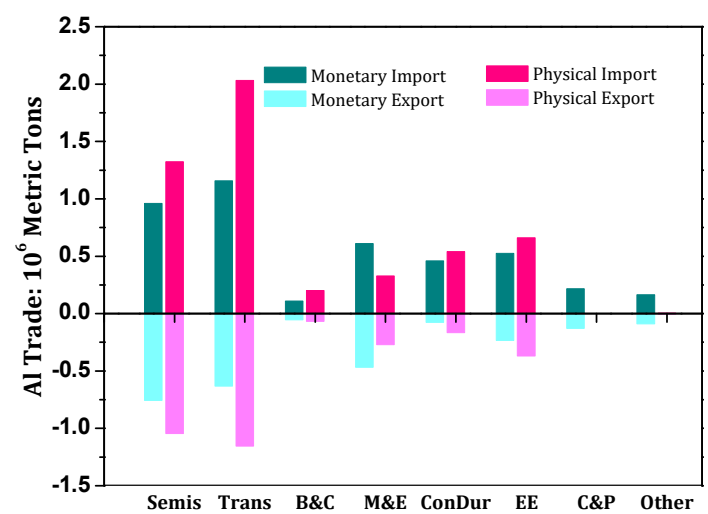

(a) Al Import and Export

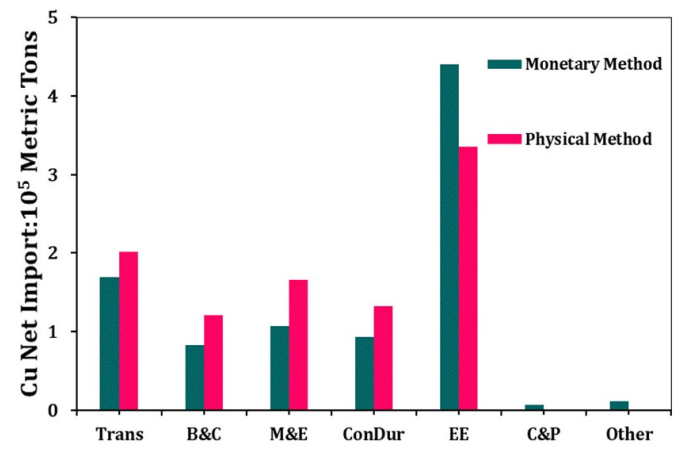

(c) $\mathrm{Cu}$ Import and Export

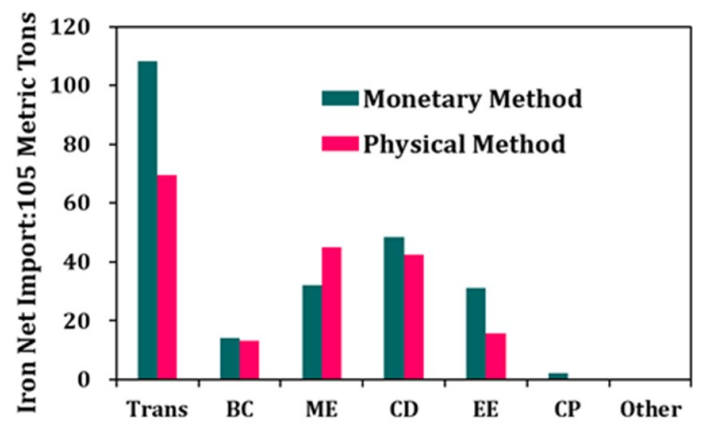

(e) Iron Import and Export

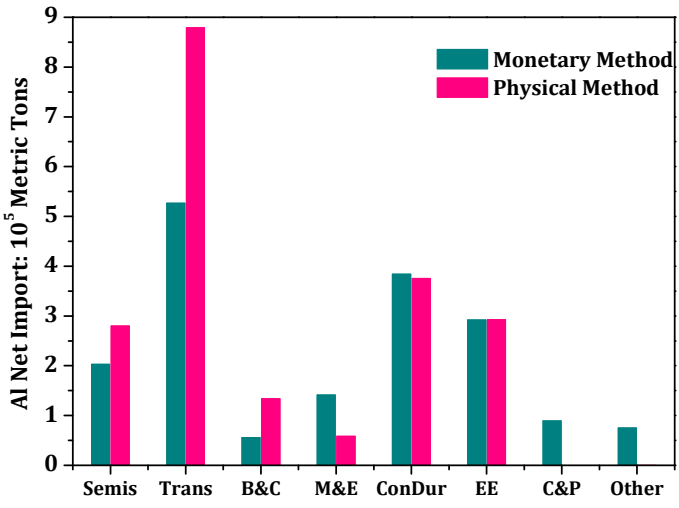

(b) Al Net Import

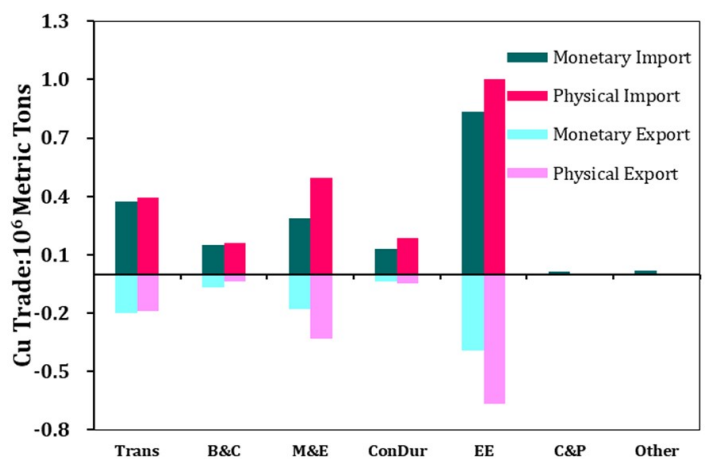

(d) $\mathrm{Cu}$ Net Import

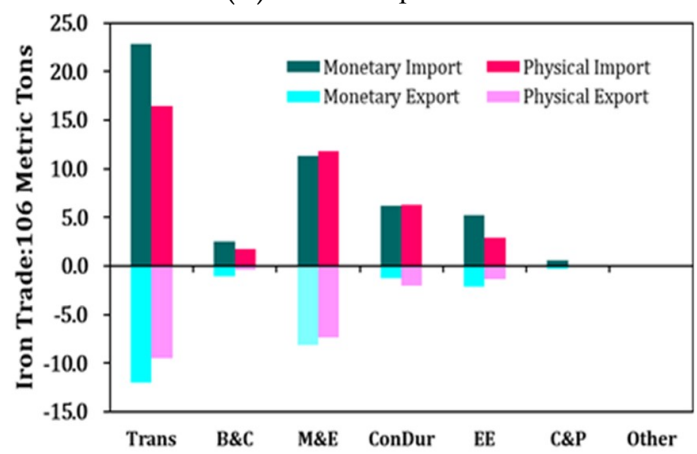

(f) Iron Net Import

Figure 2. Comparison of the import, export, and net import of aluminum, copper, and iron that were estimated by the monetary method and the physical method at the product group level (Trans: Transportation, B\&C: Building \& Construction, M\&E: Machinery, Consumer Durables, EE: Electrical Engineering, C\&P: Containers \& Packaging).

Both estimating methods demonstrate that the Trans product group contributed the highest (but not the dominating) percentage of the U.S. hidden trade of aluminum and iron embedded in final products in 2007 (Figure 3a,c). For example, the share of the Trans product group in total net import of final products were $34 \%$ and $51 \%$ according to the monetary method and the physical method, respectively for aluminum, and for iron, the shares were $46 \%$ and $37 \%$ with both methods, respectively. The highest percentage of the U.S. hidden trade of copper embedded in final products in 2007 (Figure 3b) was from EE for both import and export sections. Additionally, for net import, the highest percentage was from B\&C, taking $48 \%$ and $35 \%$ according to the monetary method and the physical method, 
respectively. This means that the U.S. probably has more advantages in manufacturing EE products than in producing $B \& C$ products. In the monetary method, about less than $5 \%$ of net import came from the Other product group for three metals, meaning that this product group was relatively unimportant but should not be completely neglected. As for aluminum, it is interesting to see that (in the monetary method) the C\&P and B\&C product groups contributed only $7-8 \%$ and $3-5 \%$ of the total trade of final products, although they accounted for about $22 \%$ and $15 \%$ of domestic shipments of ingots and mill products in 2007 [40], respectively. This indicates that the U.S. domestic markets probably prefer products produced domestically in these two product groups.

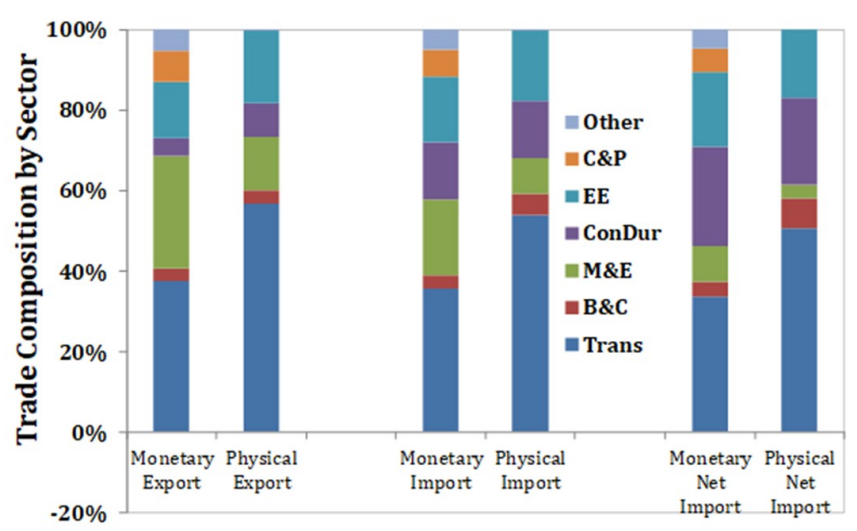

(a) Al trade

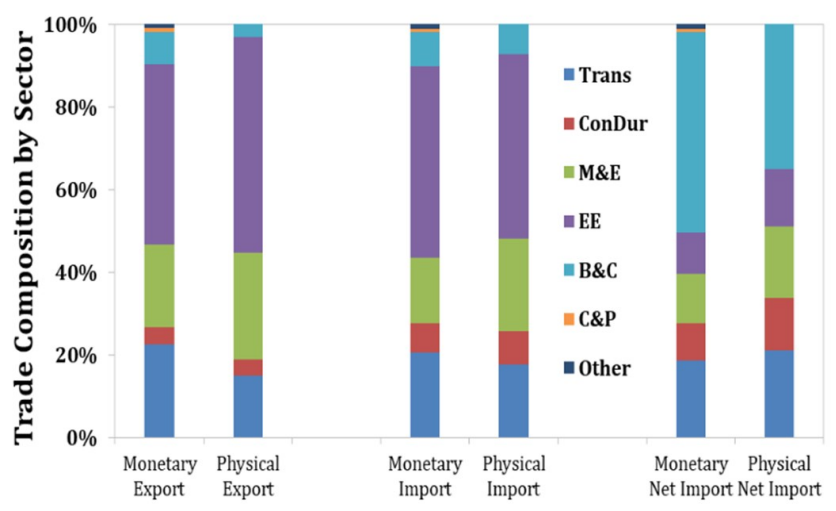

(b) Copper trade

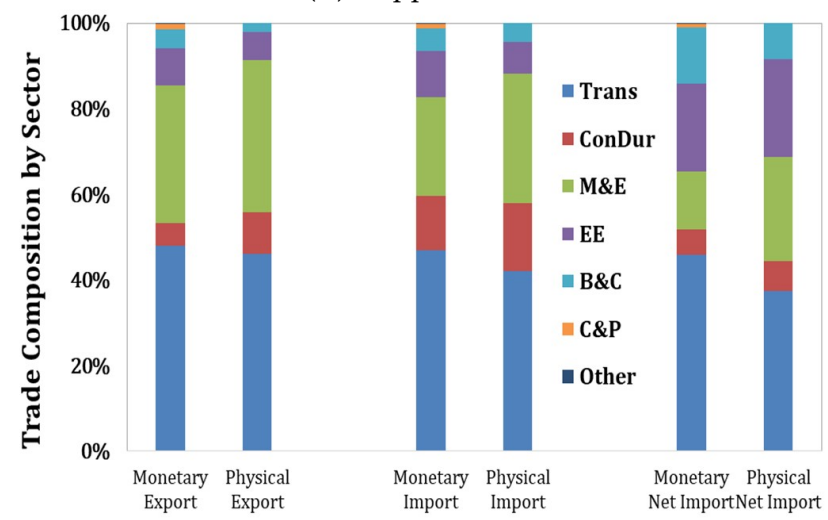

(c) Iron trade

Figure 3. Compositions of aluminum, copper, and iron trade embedded in final products estimated by the two methods.

Due to the constraints of data, we compared the sub-product group level for Trans product group and the sub-sub-product group level for Road Trans just for aluminum. A comparison at the 
sub-product group level for Trans product group reveals that the two estimating methods match pretty well in three aspects (Figure 4): (1) the trade of Trans products are dominated by the Road sub-product group, especially automobiles and light trucks; results demonstrate that U.S. is a net importer of almost all Road Trans facilities; (2) the trade of Air Trans products are relatively small but should not be ignored; it is in this sub-product group that U.S. is a net exporter of aluminum, revealing the competitive advantage of the United States in the global aviation industry; (3) the trade of aluminum embedded in Marine and Rail Trans products are very small and seem ignorable compared to other Trans products. However, substantial differences can be observed between these two methods (Table S3 in Supplementary Materials and Figure 4.): (1) according to the physical method, there are substantial net import of aluminum embedded in some Trans products that are difficult to know whether they are Air, Road, Marine, or Rail products, such as "Internal combustion engines", but this challenge does not exist for the monetary method; (2) the trade of aluminum embedded in Road Trans facilities estimated by the physical method are higher than those estimated by the monetary method.

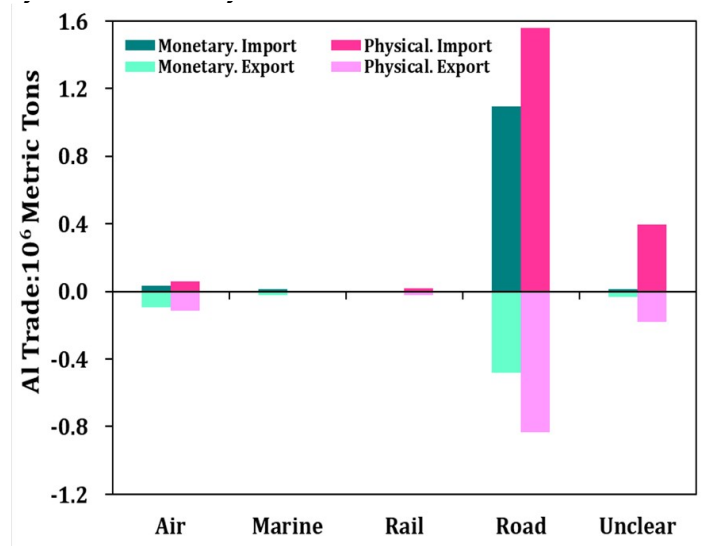

(a) Import and Export

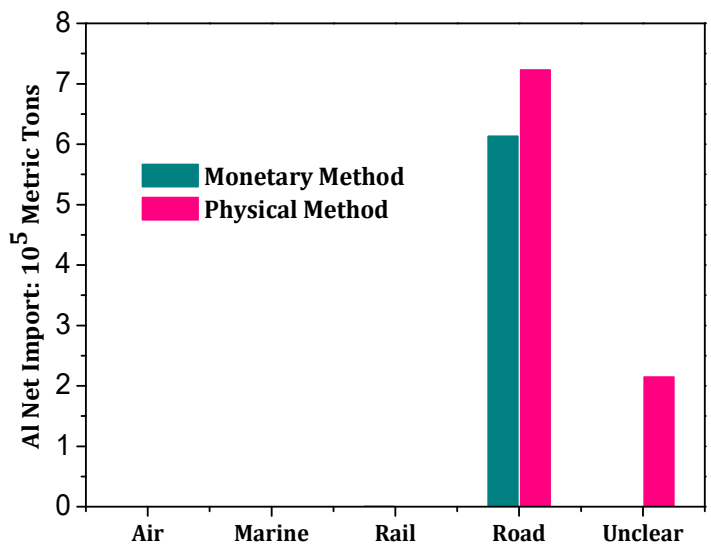

(b) Net Import

Figure 4. Comparison of the import, export, and net import of aluminum estimated by the monetary method and the physical method for the transportation of sub-product groups. (The "Unclear" sub-product group refers to those products that may be used as air, marine, rail, or road facilities, such as "Internal combustion engines".)

Further comparisons at the sub-sub-product group level for Road Trans facilities reveal both similarity and differences between the two methods again. If all Road Trans products are roughly classified into four sub-sub-product groups that are indicated by four areas with different colors (orange, cyan, green, and purple) in Figure 5, we observe from these pie charts that the relative proportions of the four areas are similar between results estimated by the two methods for both import and export. For example, the shares of orange, cyan, green, and purple areas are $29 \%, 18 \%, 45 \%$, and $8 \%$ in the export estimated by the monetary method, respectively, while they are $26 \%, 20 \%, 53 \%$, and $1 \%$ in the export estimated by the physical method, respectively. However, the main difference is that products in each sub-sub-product groups are classified and named in different ways and details. For example, the orange area contains "Automobile" and "Light truck and utility vehicle" in the monetary method, but contains "Passenger motor cars, other than buses" and "Buses, including trolleybuses" in the physical method (Figure 5 and Table S3 in Supplementary Materials). This difference results in the challenge of comparing aluminum trade embedded in specific Road Trans facilities.

In fact, although aluminum trade estimated by the two methods are comparable for product groups and for Trans sub-product groups (or even Trans sub-sub-product groups as illustrated by the four areas in Figure 5) as described above, it is very difficult to do the comparison at the level of specific products, because products are generally identified and named in different ways and details in the two product lists (Table S3, Supplementary Materials). For example, there are five products that can be reasonably identified as home appliances in the monetary method (Table S3, Supplementary 
Materials), including "household refrigerator and home freezer", "household laundry equipment", "small electrical appliance", "household cooking appliance", and "other major household appliance"; but there are about 13 products that may be regarded as home appliances in the physical method (Table S3, Supplementary Materials), including "domestic refrigerators, electrical", "domestic washing machines", "domestic appliances, nonelectrical", "electro mechanical domestic appliances ness", and nine others. This means that, although a small portion of these products in the two methods seem to match each other pretty well (such as that "household refrigerator and home freezer" seems to match "domestic refrigerators, electrical", and "household laundry equipment" seems to match "domestic washing machines"), the two product lists in most cases do not match each other product by product (such as that the other three home appliances in the monetary method cannot find corresponding products in the physical method). This situation exists in all product groups and is more obvious in the M\&E product group, in which there are more than 40 products in each product list, with a product in one list probably distributed into several products in another list and vice versa (Table S3, Supplementary Materials).

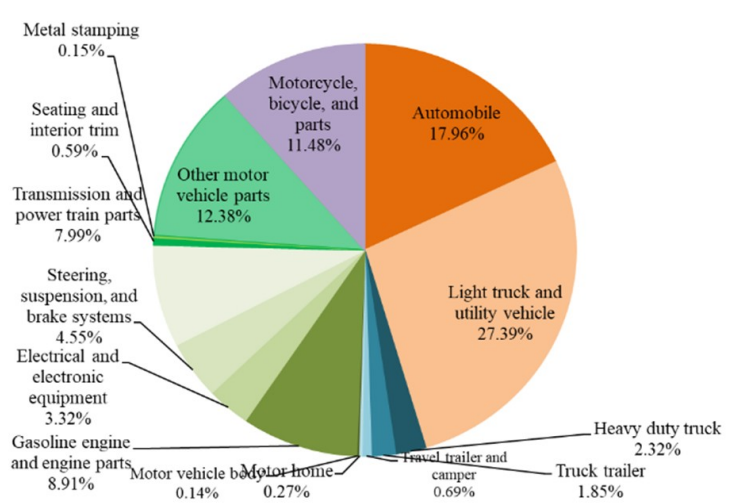

(a) Import, Monetary

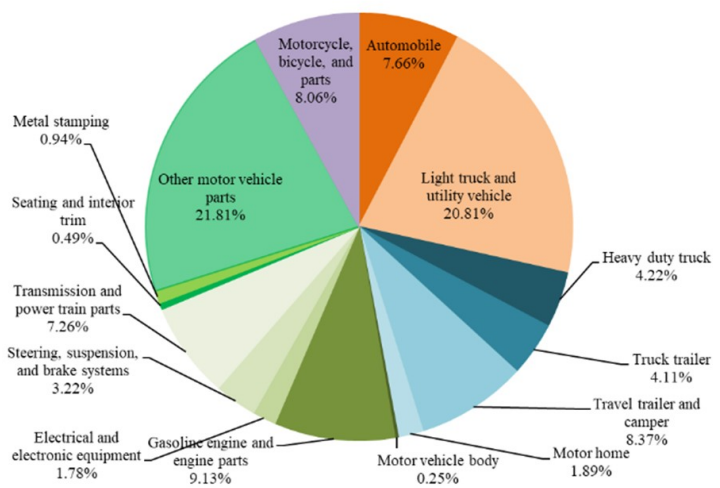

(c) Export, Monetary

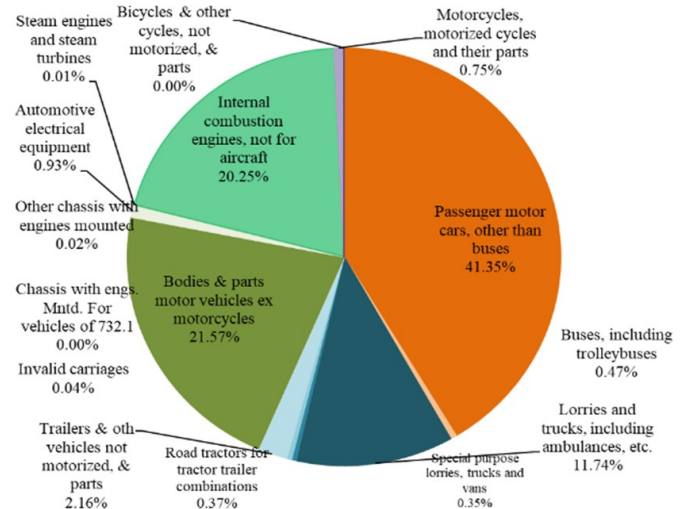

(b) Import, Physical

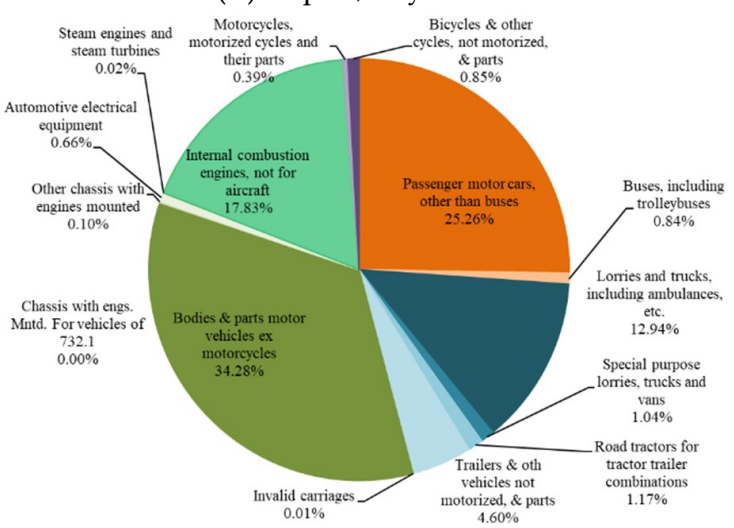

(d) Export, Physical

Figure 5. Comparison of the compositions of aluminum import and export embedded in Road Transportation facilities estimated by the two methods. Each pie chart can be roughly divided into four areas: (a) orange area represents automobiles, light trucks, and buses; (b) cyan area represents heavy trucks, trailers, lorries, and other special purpose vehicles; (c) green area represents various motor vehicle parts; and (d) purple area represents motorcycles and bicycles. (Internal Combustion Engines that are listed as Unclear in Figure 3 are classified into green area here).

Another challenge when comparing aluminum, copper, and iron trade at the product level is that, even for these small numbers of final products that have reasonably matched products in both lists, there usually are pretty big differences between results estimated by the two methods. For example (refer to Table S3 (Supplementary Materials) for data cited in this paragraph), the net import of "domestic washing machines" in the physical method is about 7.1 TMTs and 35\% higher than the net 
import of "household laundry equipment" in the monetary method. The net import of "pumps and centrifuges" in the physical method is about 4.0 TMTs and 53\% higher than the net import of "pump and pumping equipment" in the monetary method. More obviously, for wires and cables, the total net import of relevant products identified in the physical method list ("wire, cables, ropes, etc. not insulated, aluminum" and "insulated wire and cable") is about 393 TMTs and over 5 times higher than the total net import of relevant products identified in the monetary method list ("communication and energy wire and cable" and "wiring device"). This problem, together with the difficulty of matching products in the two lists, indicates that the comparison of metals trade embedded in final products estimated by the two methods can only be reasonably done at the end-use product group level, but not at the specific product level.

\section{Discussion}

Using two methods for estimating the hidden trade of metals embedded in final products is effective. However, the comparison for specific products is challenging or does not generate consistent enough results. This may result from several reasons: (1) products are classified and named according to different standards with different details in the two methods; for example, a specific product in one list (e.g., Table S3, Supplementary Materials) may be classified into several products in another list (e.g., Table S3, Supplementary Materials), and these products in turn may be distributed into some other products in the first list; (2) the SITC-1 system of classifying products used in the physical method was set up in the early 1960s and is too old, which results in the problem that some recently developed products, such as electronic products, are not well categorized and highlighted in the physical method; and (3) there are uncertainties in metals concentrations of final products, no matter in the physical method or in the monetary method.

Compared to the physical method that has been used at least since 2002 in a study of determining European copper trade embedded in final products [41,42], it was not until 2011 that the monetary method was first reported by Japanese researchers specifically for determining metal trade [21]. The latter is thus newer and less widely used up to now. However, its advantages of (1) relying on monetary trade data that are more widely available than the physical trade data and (2) applying metal concentration data that can be easily generated by the WIO-MFA model make the monetary method very promising and useful in building global trade networks of metals and other materials [30-32]. In addition, this study's finding (that the metals trade embedded in final products estimated by the two methods are not too much different at the end-use product group level) suggests that the monetary method can be pretty reliable if the global trade networks are built for all final products or for products in an end-use product group.

Nevertheless, researchers have to keep in mind some potential challenges when using the monetary method: (1) only U.S., Japan, and South Korea provide IO tables with about 400 product groups that are detailed enough for determining metal concentrations in products, and metal concentrations estimated using different country's IO tables could be different; therefore, researchers will have to carefully speculate with these three countries' IO data when trying to use them for building global metal trade networks; (2) IO tables with about 400 sectors are usually compiled every several years and need some years to be made (e.g., U.S. 400-sectors IO tables are made every five years and the most recent version is for 2007 [22]), and therefore researchers will not be able to get annual and up-to-date metal concentration data; (3) careful matching between the monetary trade data (categorized either by the HS or the SITC 1-4 systems) and the IO sectors will have to be made; and (4) classifying all products into even 400 sectors is actually very rough, especially if compared to the HS standard of categorizing products by thousands of 6-digit- or 8-digit-code products. Therefore, results provided by the monetary method are more reliable at the macro end-use product group level (e.g., transportation) than at the specific IO sectors or product (e.g., automobile) level.

The physical method also has the advantages and disadvantages. The trade data such as import, export, and net import of final products are available on the UN Comtrade Database for more than 
200 countries, so this method can be wildly used. The equations of calculate the metal concentrations is easy to use and understand. However, the challenges of using the physical method include: (1) there are some different visions of both SITC and HS systems, so using different versions of final products may obtain different results; (2) products from different countries may have different metal concentrations, so it is hard to popularize this method when involving more than one country. It is hard to define which one, the physical method or monetary method, has more accurate results, because they both have virtues and uncertainties.

\section{Conclusions}

Using the U.S. aluminum, copper, and iron trade in 2007 as a case, this study provides, to our knowledge, the first comparison of the trade of metals embedded in final products estimated by two different methods. Despite the differences in the exact amount of metals trade (which are unavoidable and reasonable), the results generated by the two methods are consistent with each other pretty well for total semis, at the level of end-use product groups for final products, and for net trade flows. Especially, the two methods provide completely the same results in determining whether U.S. was a net importer or net exporter of semis and final products at the end-use product group level.

Using two methods for estimating the hidden metals embedded in final products and comparing the results is to discuss the uncertainties of two methods. The macrography results of the two methods are generally accurate, but it is difficult to perform accurate calculation in microscopy. Using two methods in itself is to crosscheck the uncertainties of the two methods. Please note that the comparison provided by this study is just for three metals, in one country, and for a one-year snapshot, the findings are thus probably not complete and universal enough. Given that there are more and more studies on material trade flow analysis (such as those for multi-country aluminum trade in 2008 [16], China's dynamic aluminum trade in the period 1980-2009 [29], and global trade network for cobalt, neodymium, and platinum in 2005 [30]), it is both feasible and necessary to do similar comparisons for more materials, in more countries/territories, and for dynamic time periods. For example, it is possible to change the research objects from metals to less valuable materials paper to see if we can get the different results by using the two methods. Additionally, we expect there can be more researches which can use this method for one metal dynamic analysis of one country on a long-term scale to see if changes in unit price of the product will affect the results gap of the two methods. In addition, because traded products are categorized according to both SITC and HS systems, and the SITC system has four versions while the HS system has five versions now [20], researchers may obtain different results if using different systems or different SITC/HS versions. Thus, comparisons can also be done among different product classification methods. More comparisons as proposed here will help to reveal the common features, differences, advantages, and disadvantages of different methods and different product classification methods in determining material trade embedded in final products. We thus can expect more studies on the hidden trade for more materials in more countries and for more diverse time periods with less time costs, and make hidden material trade analysis an indispensable and doable part in all future MFA studies at the country/territory level.

Supplementary Materials: The following are available online at http://www.mdpi.com/2079-9276/8/2/89/s1, Figure S1: Comparing the export, import, and net import of aluminum estimated by the physical method in this study and the former MFA Study, Table S1: Comparison of the two classification systems, Table S2: The different stages of the product (take aluminium as an example), Table S3: The list of products used in the monetary method and their aluminum trade, Table S4: The list of products used in the monetary method and their copper trade, Table S5: The list of products used in the monetary method and their iron trade, Table S6: The list and classification of final products used in the physical method in two studies.

Author Contributions: Writing of original draft preparation, W.-Q.C. and Z.-J.M.; data acquisition, W.-Q.C., S.P., T.W., and Z.-J.M.; writing of review and editing, W.-Q.C., S.P., and T.W.; visualization, W.-Q.C. and Z.-J.M.

Funding: This research was funded by the National Natural Science Foundation of China (No. 41671523) and the CAS Pioneer Hundred Talents Program. 
Acknowledgments: We thank Nick Baker, Chris Bayliss, Marlen Bertram, Michael Cusick, Ayman Elshkaki, Arnulf Grubler, Jeffrey Jones, Christine Jun, Carl Lam, Gang Liu, Philip Nuss, Jay Townley, Jinlong Wang, Chao Zhang, and Tom Graedel for providing relevant data and/or for helpful comments.

Conflicts of Interest: The authors declare no conflict of interest.

\section{References}

1. Krausmann, F.; Wiedenhofer, D.; Lauk, C.; Haas, W.; Tanikawa, H.; Fishman, T.; Miatto, A.; Schandl, H.; Haberl, H. Global socioeconomic material stocks rise 23-fold over the 20th century and require half of annual resource use. Proc. Natl. Acad. Sci. USA 2017, 114, 1880-1885. [CrossRef]

2. Bruno Oberle, S.B.; Hatfield-Dodds, S.; Hellweg, S.; Schandl, H.; Clement, J. Global Resource Outlook 2019; International Resource Panel of the United Nations Environment Programme: Paris, France, 2019.

3. Wiedmann, T.O.; Schandl, H.; Lenzen, M.; Moran, D.; Suh, S.; West, J.; Kanemoto, K. The material footprint of nations. Proc. Natl. Acad. Sci. USA 2015, 112, 6271-6276. [CrossRef] [PubMed]

4. Pierluigi Toma, S.M.; Miglietta, P.P. Natural Resource Use Efficiency and Economic Productivity. In Life Cycle Approaches to Sustainable Regional Development; Routledge - Taylor and Francis Group: New York, NY, USA, 2017; pp. 143-148.

5. Lamastra, L.; Miglietta, P.P.; Toma, P.; De Leo, F.; Massari, S. Virtual water trade of agri-food products: Evidence from italian-chinese relations. Sci. Total Environ. 2017, 599-600, 474-482. [CrossRef]

6. Miglietta, P.P.; Morrone, D. Managing Water Sustainability: Virtual Water Flows and Economic Water Productivity Assessment of the Wine Trade between Italy and the Balkans. Sustainability 2018, 10, 543. [CrossRef]

7. Miglietta, P.P.; Giove, S.; Toma, P. An optimization framework for supporting decision making in biodiesel feedstock imports: Water footprint vs. import costs. Ecol. Indic. 2018, 85, 1231-1238. [CrossRef]

8. Zhang, C.; Chen, W.Q.; Ruth, M. Measuring material efficiency: A review of the historical evolution of indicators, methodologies and findings. Resour. Conserv. Recycl. 2018, 132, 79-92. [CrossRef]

9. Graedel, T.E.; Harper, E.M.; Nassar, N.T.; Nuss, P.; Reck, B.K. Criticality of metals and metalloids. Proc. Natl. Acad. Sci. USA 2015, 112, 4257-4262. [CrossRef]

10. Liang, S.; Wang, Y.; Cinnirella, S.; Pirrone, N. Atmospheric Mercury Footprints of Nations. Environ. Sci. Technol. 2015, 49, 3566-3574. [CrossRef] [PubMed]

11. Johnson, J.; Graedel, T. The "Hidden" Trade of Metals in the United States. J. Ind. Ecol. 2008, 12, 739-753.

12. Fischer-Kowalski, M.; Krausmann, F.; Giljum, S.; Lutter, S.; Mayer, A.; Bringezu, S.; Moriguchi, Y.; Schütz, H.; Schandl, H.; Weisz, H. Methodology and Indicators of Economy-wide Material Flow Accounting. J. Ind. Ecol. 2011, 15, 855-876. [CrossRef]

13. Wang, T.; Muller, D.B.; Graedel, T.E. Forging the anthropogenic iron cycle. Environ. Sci. Technol. 2007, 41, 5120-5129. [CrossRef] [PubMed]

14. Chen, W.Q.; Graedel, T.E. Dynamic analysis of aluminum stocks and flows in the United States: 1900-2009. Ecol. Econ. 2012, 81, 92-102. [CrossRef]

15. Reck, B.K.; Müller, D.B.; Rostkowski, K.; Graedel, T.E. Anthropogenic nickel cycle: Insights into use, trade, and recycling. Environ. Sci. Technol. 2008, 42, 3394-3400. [CrossRef] [PubMed]

16. Liu, G.; Muller, D.B. Mapping the Global Journey of Anthropogenic Aluminum: A Trade-Linked Multilevel Material Flow Analysis. Environ. Sci. Technol. 2013, 47, 11873-11881. [CrossRef] [PubMed]

17. Liu, G.; Bangs, C.E.; Müller, D.B. Stock dynamics and emission pathways of the global aluminium cycle. Nat. Clim. Chang. 2012, 3, 338-342. [CrossRef]

18. Cao, Z.; Shen, L.; Løvik, A.N.; Muüller, D.B.; Liu, G. Elaborating the History of Our Cementing Societies: An in-Use Stock Perspective. Environ. Sci. Technol. 2017, 51, 11468-11475. [CrossRef] [PubMed]

19. Dittrich, M.; Bringezu, S. The physical dimension of international trade. Ecol. Econ. 2010, 69, $1838-1847$. [CrossRef]

20. United Nations. UN Comtrade Database. Available online: http://comtrade.un.org/data/ (accessed on 10 March 2016).

21. Nakajima, K.; Nansai, K.; Matsubae, K.; Kondo, Y.; Kagawa, S.; Inaba, R.; Nakamura, S.; Nagasaka, T. Identifying the Substance Flow of Metals Embedded in Japanese International Trade by Use of Waste Input-Output Material Flow Analysis (WIO-MFA) Model. ISIJ Int. 2011, 51, 1934-1939. [CrossRef] 
22. U.S. BEA. Input-Output Accounts Data. Available online: http://www.bea.gov/industry/io_annual.htm\#data (accessed on 1 April 2015).

23. Japanese Ministry of Internal Affairs and Communications. Input-Output Tables for Japan. Available online: http://www.soumu.go.jp/english/dgpp_ss/data/io/index.htm (accessed on 5 October 2015).

24. Reck, B.K.; Chambon, M.; Hashimoto, S.; Graedel, T.E. Global stainless steel cycle exemplifies China's rise to metal dominance. Environ. Sci. Technol. 2010, 44, 3940-3946. [CrossRef]

25. Harper, E.M.; Graedel, T.E. Illuminating tungsten's life cycle in the United States: 1975-2000. Environ. Sci. Technol. 2008, 42, 3835-3842. [CrossRef]

26. Harper, E.M.; Kavlak, G.; Graedel, T.E. Tracking the Metal of the Goblins: Cobalt's Cycle of Use. Environ. Sci. Technol. 2012, 46, 1079-1086. [CrossRef]

27. Izard, C.; Muller, D. Tracking the devil's metal: Historical global and contemporary US tin cycles. Resour. Conserv. Recycl. 2010, 54, 1436-1441. [CrossRef]

28. Chen, W.-Q.; Shi, L.; Qian, Y. Substance flow analysis of aluminium in mainland China for 2001, 2004 and 2007: Exploring its initial sources, eventual sinks and the pathways linking them. Resour. Conserv. Recycl. 2010, 54, 557-570. [CrossRef]

29. Chen, W.Q.; Shi, L. Analysis of aluminum stocks and flows in mainland China from 1950 to 2009: Exploring the dynamics driving the rapid increase in China's aluminum production. Resour. Conserv. Recycl. 2012, 65, 18-28. [CrossRef]

30. Nansai, K.; Nakajima, K.; Kagawa, S.; Kondo, Y.; Suh, S.; Shigetomi, Y.; Oshita, Y. Global Flows of Critical Metals Necessary for Low-Carbon Technologies: The Case of Neodymium, Cobalt, and Platinum. Environ. Sci. Technol. 2014, 48, 1391-1400. [CrossRef]

31. Nakajima, K.; Nansai, K.; Matsubae, K.; Nagasaka, T. Material Flow of Iron in Global Supply Chain. ISIJ Int. 2014, 54, 2657-2662. [CrossRef]

32. Nakajima, K.; Otsuka, Y.; Iwatsuki, Y.; Nansai, K.; Yamano, H.; Matsubae, K.; Murakami, S.; Nagasaka, T. Global supply chain analysis of nickel: Importance and possibility of controlling the resource logistics. Metall. Res. Technol. 2014, 111, 339-346. [CrossRef]

33. Pauliuk, S.; Wang, T.; Muller, D.B. Moving Toward the Circular Economy: The Role of Stocks in the Chinese Steel Cycle. Environ. Sci. Technol. 2012, 46, 148-154. [CrossRef]

34. Chen, W.Q.; Graedel, T.E.; Nuss, P.; Ohno, H. Building the Material Flow Networks of Aluminum in the 2007 US Economy. Environ. Sci. Technol. 2016, 50, 3905-3912. [CrossRef]

35. Nuss, P.; Ohno, H.; Chen, W.Q.; Graedel, T.E. Comparative Analysis of Metals Use in the United States Economy. Resour. Conserv. Recycl. 2019. in Press. [CrossRef]

36. The Aluminum Association. End Use Guide for Reporting Shipments of Semi-Fabricated Aluminum Products; The Aluminum Association: Arlington, VA, USA, 2007.

37. Liu, G.; Bangs, C.E.; Muller, D.B. Unearthing Potentials for Decarbonizing the US Aluminum Cycle. Environ. Sci. Technol. 2011, 45, 9515-9522. [CrossRef] [PubMed]

38. Buchner, H.; Laner, D.; Rechberger, H.; Fellner, J. Dynamic Material Flow Modeling: An. Effort to Calibrate and Validate Aluminum Stocks and Flows in Austria. Environ. Sci. Technol. 2015, 49, 5546-5554. [CrossRef] [PubMed]

39. International Aluminium Institute. Regional Mass Flow Models. Available online: http://www.worldaluminium.org/publications/ (accessed on 20 August 2016).

40. The Aluminum Association. Aluminum Statistical Review for 2009; The Aluminum Association: Arlington, VA, USA, 2010.

41. Graedel, T.E.; Bertram, M.; Fuse, K.; Gordon, R.B.; Lifset, R.; Rechberger, H.; Spatari, S. The contemporary European copper cycle: The characterization of technological copper cycles. Ecol. Econ. 2002, 42, 9-26. [CrossRef]

42. Spatari, S.; Bertram, M.; Fuse, K.; Graedel, T.E.; Rechberger, H. The contemporary European copper cycle: 1 year stocks and flows. Ecol. Econ. 2002, 42, 27-42. [CrossRef]

(C) 2019 by the authors. Licensee MDPI, Basel, Switzerland. This article is an open access article distributed under the terms and conditions of the Creative Commons Attribution (CC BY) license (http://creativecommons.org/licenses/by/4.0/). 